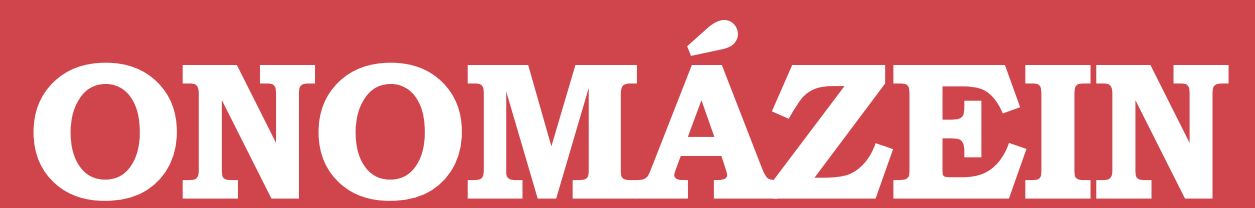

Revista semestral de lingüística, filología y traducción
PONTIFICIA UNIVERSIDAD CATÓLICA DE CHILE FACULTAD DE LETRAS

\title{
Variación diatópica, discursiva y fonética de /s/ codal en el habla de profesionales chilenos ${ }^{12}$
}

Coda/s/ regional, discursive and phonetic variation in the speech of a group of Chilean university professionals

\section{Karina Cerda-0ñate}

Universidad de Concepción

Chile

\section{Jaime Soto-Barba \\ Universidad de Concepción Chile}

\section{Darío Fuentes-Grandón}

Universidad de Concepción

Chile

\section{Nahida Hamdan Rosales}

Universidad de Concepción

Chile

Karina Cerda: Departamento de Español, Facultad de Humanidades y Arte, Universidad de Concepción, Chile. | Correo electrónico: karinacerda@udec.cl

Darío Fuentes: Departamento de Español, Facultad de Humanidades y Arte, Universidad de Concepción, Chile. | Correo electrónico: dariofuentes@udec.cl Jaime Soto: Departamento de Español, Facultad de Humanidades y Arte, Universidad de Concepción, Chile. | Correo electrónico: jstot@udec.cl

Nahida Hamdan Rosales: Departamento de Español, Facultad de Humanidades y Arte, Universidad de Concepción, Chile. | Correo electrónico: nahida.hamdan.rosales@gmail.com 


\section{Resumen}

El siguiente trabajo de investigación se enmarca en la sociolingüística cuantitativa y busca dar cuenta del fenómeno de la variación de /s/ en posición codal en una muestra de profesionales chilenos. Además de describir la variación del fonema /s/ en posición codal, este estudio busca determinar la variación de /s/ codal en relación con 3 variables: ciudad, modalidad discursiva (lectura en voz alta y entrevista semiespontánea) y contexto fónico (interior y final de pala- bra). En virtud de esto, se seleccionó una muestra de $32^{3}$ informantes de 8 ciudades capitales chilenas, y se realizó un análisis auditivo clásico de $n=3.264$ realizaciones de /s/ codal. Los resultados del análisis descriptivo de los datos y de la prueba de $\chi 2$ de Pearson indican que las variables modalidad discursiva y contexto fónico tienen un efecto en la variación de /s/ codal en los datos de la muestra; por su parte, el análisis en relación con la variable ciudad no fue concluyente.

Palabras clave: fonética del español; español de Chile; sociolingüística;/s/codal.

\section{Abstract}

The present article falls within the framework of a quantitative and descriptive sociolinguistics perspective and it aims to describe the phenomenon of coda $\mathrm{s} / \mathrm{v}$ ariation in a sample of college-educated subjects, speakers of Chilean Spanish. Moreover, this research aims to describe the variation of coda/s/ in Chilean Spanish regarding three variables: city of origin of the informant, discourse modality (reading aloud and semispontaneous interview) and phonetic context (wordinterior and word-final). In order to do so, a sample of
32 informants from 8 different Chilean regional capital cities was selected from FONDECYT ${ }^{4}$ Project N.1120886. The sample was analyzed by means of an auditory classical analysis, which considered $n=3.264$ tokens of coda $\mathrm{s} / \mathrm{s}$. The results from the descriptive analysis and from a Pearson's chi-squared test show that the variables "discourse modality" and "phonic context" have an effect on the variation of coda /s/in the sampled data. On the other hand, the analysis regarding the diatopic variable and its effect on coda/s/variation was not conclusive.

Keywords: Spanish phonetics; Chilean Spanish; sociolinguistics; coda/s/.

1 Resultados parciales del proyecto Fondecyt N¹120886: "Descripción fonético-fonológica de un modelo de pronunciación enseñable del español culto de Chile", dirigido por el Dr. Jaime Soto-Barba.

2 Agradecimientos a Hernán E. Pérez (UDEC), Gamal Cerda Etchepare (UDEC), Camilo Quezada Gaponov (UC), Mónica Tapia Ladino (UCSC), Gastón Salamanca (UDEC), Domingo Román M. (UC) y Héctor Ortiz-Lira (UMCE) por sus valiosas sugerencias.

3 Submuestra de la muestra total del proyecto Fondecyt N¹120886: "Descripción fonético-fonológica de un modelo de pronunciación enseñable del español culto de Chile”, dirigido por el Dr. Jaime Soto-Barba.

4 Chilean National Science and Technology Research Fund (FONDECYT) 


\section{Introducción}

Existen numerosos estudios acerca de la variación en el español hispanoamericano en la realización del fonema /s/ en posición codal. Esto se debe a que la variación de /s/ es uno de los rasgos dialectales más característicos de Hispanoamérica, además de ser uno de los fonemas con más alta frecuencia en el español (Alarcos Llorach, 1961).

Los primeros datos sobre el estudio de /s/ codal fueron aportados por Cedergreen (1973), quien indica tres variantes para el español de Panamá: sibilante, aspirada y cero fonético. Más tarde, Terrell (1975 en Samper, 2001) distinguió las mismas variantes para el fonema /s/ en posición codal en el español de la norma culta de La Habana; es decir, variante sibilante, variante aspirada y elisión del fonema. Por su parte, Samper (2001) propuso 3 zonas de acuerdo con la literatura existente sobre la variación de /s/ codal en el español. En la primera, denominada zona de dialectos conservadores, se tiende a producir este fonema de modo sibilante [s] (español de San José de Costa Rica (Quesada, 1988); español de Lima (Caravedo, 1990); español de Rosario (Donni de Mirande, 1991); español de Toledo (Calero, 1993); y español de Getafe (Martín Butragueño, 1995))5. En la segunda zona, la tendencia es a producir una variante aspirada [h] por sobre las otras variantes (español de El Hierro, Canarias (Pérez Martín, 1995); español de Buenos Aires, norma culta (Terrell, 1978); español de Concepción, norma culta (Valdivieso y Magaña, 1991); español de Las Palmas (Samper, 1990, 1995); español de Puerto Cabello, Venezuela (Navarro, 1987); español de La Habana, norma culta (Terrell, 1975, 1979); español de Córdoba, España (Iglesias, 2000); español de San Juan, Puerto Rico (López Morales, 1983)). Por último, en la tercera zona, la tendencia es a elidir el fonema $(\varnothing)^{6}$ (es- pañol de Panamá (Cedergreen, 1973); español de Mérida, Venezuela (Longmire, 1976); español de Costa granadina (García Marcos, 1990); español de Santo Domingo (Núñez, 1980); español de Melilla, Madrid (Ruiz, 1997); español de Santiago, República Dominicana (Alba, 1982, 1990)).

En Chile, el fonema/s/ ha sido descrito como una consonante dorsoalveolar sorda (Oroz, 1966), predorsopostdental (Ramírez, 1971), predorsoalveolar (Wagner, 1967; Valdivieso y Magaña, 1988; Tassara y Duque, 1987) y como predorso-prepalatal convexa (Lagos y Olivera, 1988; Cepeda, 1991). Todos estos autores mencionan las mismas variantes para la realización del fonema /s/: fricativa predorsoalveolar [s], fricativa glotal [h] y elidida ( $\varnothing$ ). Entre los estudios sobre variación alofónica de /s/ en posición codal en el español de Chile, destacan las investigaciones de Tassara y Duque (1987), Valdivieso y Magaña (1987, 1988 y 1991), Valdivieso, Tassara, Magaña y Duque (1988), Cepeda (1990, 1995), Valencia (19931994), Borland-Delorme (2004), Pérez (2007) y Soto-Barba (2011).

Valdivieso y Magaña (1987) describieron la realización de /s/ en 16 hablantes de estrato sociocultural alto de Concepción, en situación de lectura, y encontraron que el grupo masculino prefirió el alófono [h] (56,1\%) por sobre [s] (41,2\%) y la variante elidida $(\varnothing)(2,7 \%)$; en cambio, el grupo femenino privilegió el alófono [s] (54,4\%) por sobre [h] (43\%) y la variante elidida ( $\varnothing)(2,6 \%)$. En Valparaíso, Tassara y Duque (1987) también describieron la realización de /s/ en el estrato sociocultural alto en situación de lectura y consignaron que, si bien existía bastante distribución, la aspiración superaba a la realización del fonema predorsoalveolar en ambos grupos. Ahora bien, a diferencia de Concepción, en Valparaíso, el grupo femenino presentó una mayor frecuencia de realizaciones de [h] (58\%) en oposición a [s] (39,

5 El término "sibilante" puede aludir también a "mantención” o "retención” de /s/ y a la zona de articulación "predorsodentoalveolar".

6 Entendemos el símbolo $\varnothing$ como la elisión del fonema /s/ 
$8 \%)$, y los hombres presentaron un $45,7 \%$ de realizaciones del alófono [s] y un 51,1\% del alófono [h]. Posteriormente, Valdivieso y Magaña (1988, 1991) informaron que en Concepción se observaba distribución entre los alófonos [s] y [h] y una baja ocurrencia de elisión en los hablantes de estrato sociocultural alto de Concepción en situación de lectura; en cambio, en habla espontánea, registraron un predominio de [h].

En Valdivia, Cepeda (1990) registró un predominio de la variante sibilante en los hombres y las mujeres con un $51,6 \%$ y un $50,1 \%$, respectivamente, en hablantes de clase media de Valdivia en situación de entrevista. Al igual que en Concepción y Valparaíso, observó también un número importante de realizaciones de [h] tanto en el grupo masculino (32,4\%) como en el femenino (34\%) y un número no menor de elisiones, tanto en los grupos masculino como en el femenino, con $16 \%$ y $15,9 \%$, respectivamente.

Cepeda (1995, en Ortiz-Lira y Saavedra, 2003) realizó un estudio de 16.006 casos de /s/ en posición final de palabras. Estas realizaciones fueron obtenidas de un corpus de 34 hablantes de Valdivia, que pertenecían a 3 grupos socioeconómicos y etarios diferentes. La autora detectó alófonos sibilantes (africados y fricativos), no sibilantes (aproximantes y oclusivos, con distensión audible) y elisiones ( $\varnothing$ ). Los resultados de Cepeda (1995, en Ortiz-Lira y Saavedra, 2003) señalaron que la pronunciación de [s] es propia de los sujetos femeninos del estrato alto y de la generación mayor, mientras que la elisión $(\varnothing)$ caracterizaría a los sujetos masculinos del estrato social bajo y de la generación joven. Por su parte, Valencia (1995) trabajó con un corpus de habla de adolescentes de Santiago de Chile. Los resultados de Valencia (1995) informan que en todos los contornos la variante más realizada es la [h], seguida de la elisión y, posteriormente, de las realizaciones sibilante y glotal oclusiva.

Posteriormente, Pérez (2007) se refirió a la realización de /s/ en el habla de un corpus extraído de los noticieros de la televisión chilena. Es- pecíficamente, el autor estudió la variación del fonema/s/ en relación con el modo discursivo y señaló que en el habla espontánea existe una alta probabilidad de ocurrencia de [h], una probabilidad media de elisión $(\varnothing)$ y una probabilidad escasa de que ocurra [s]. En cambio, en el modo denominado "habla no-espontánea, enunciar lo escrito para ser hablado", existiría una alta probabilidad de variación, que se distribuye entre [s] y [h], y una posibilidad media de elisión ( $\varnothing$ ).

Así también, Soto-Barba (2011) estudió el habla urbana y rural de la provincia de Ñuble ( $n=$ 1.200) y señaló que para el grupo urbano alto, urbano bajo y rural bajo hay un predominio de la realización del alófono aspirado [h]. Así también, constató que la realización del alófono [s] es más frecuente en el sector urbano, con un $20 \%$ de realizaciones en el grupo urbano alto y un $16 \%$ de realizaciones en el grupo urbano bajo, en contraste con un $3 \%$ en el grupo rural bajo. Finalmente, la realización de la variante elidida sería más común en el grupo rural bajo, con un 13\%, en oposición a un 3\% y 5\% para los grupos urbano alto y urbano bajo, respectivamente.

Finalmente, y respecto de la revisión bibliográfica acerca de los estudios previos sobre la variación de /s/ codal en el español panhispanoamericano y, más específicamente, en el español chileno, cabe señalar que esta investigación se propuso dos objetivos. En primer lugar, aportar a la descripción del fenómeno de variación de /s/ codal en el español de Chile en la actualidad y, de esta manera, colaborar también para situarlo respecto de la variación de /s/ codal en el universo panhispanomericano (Samper, 2001). En segundo lugar, se buscó definir el efecto de tres variables (ciudad, modalidad discursiva y contexto fónico) en la variación de /s/ codal en una muestra específica de hablantes de ocho ciudades chilenas.

\section{Hipótesis}

A continuación se presentan la hipótesis nula y las hipótesis alternativas de este estudio: 
- Ho: Las variables independientes, ciudad, contexto y modalidad discursiva no tienen un efecto en la distribución de la variación de la variable dependiente /s/ en posición codal en la muestra analizada.

- Hz: La variable independiente "ciudad" tiene un efecto en la distribución de la variación de la variable dependiente "/s/ codal" en la muestra analizada.

- H2: La variable independiente "contexto fónico" tiene un efecto en la distribución de la variación de la variable dependiente "/s/ codal" en la muestra analizada.

- H3: La variable independiente "modalidad discursiva" tiene un efecto en la distribución de variación de la variable dependiente "/s/ codal" en la muestra analizada.

\section{Métodos y materiales}

\subsection{Diseño de la investigación}

Esta investigación se realizó en cuatro etapas, las cuales serán descritas a continuación.

Etapa 1. Recolección del corpus de habla espontánea

El corpus del proyecto Fondecyt No 1120886 correspondió a grabaciones y registros audiovisuales de entrevistas realizadas a 217 personas. Los informantes de la muestra eran todos profesionales, con estudios superiores completos, y provenían de ciudades representativas de las cuatro regiones geográficas del español de Chile. Estas zonas se definieron de acuerdo con lo propuesto por Wagner (2004), quien dividió a Chile en 4 zonas: zona norte (desde Arica hasta Choapa), zona centro (desde Petorca hasta Cauquenes), zona sur (desde Ñuble hasta Cautín) y zona austral (desde Valdivia hasta Tierra del Fuego). En vista de esta clasificación, los informantes de la muestra pertenecían a las ciudades de Iquique y La Serena para la zona norte; Valparaíso y Santiago para la zona centro; Concepción y Temuco para la zona sur; y Coyhaique y Punta Arenas para la zona austral. Además, cabe destacar que las entrevistas se realizaron en cada una de las ciudades mencionadas.

Una vez tomada la muestra antes mencionada, se realizó una prueba de actitudes lingüísticas mediante la plataforma de Internet Google Docs, con el propósito de filtrar la muestra y seleccionar a aquellos hablantes que presentasen una pronunciación bien valorada socialmente. La prueba fue realizada por 50 hablantes con estudios superiores, quienes evaluaron una selección aleatoria de enunciados de los informantes de la muestra. Específicamente, el test constaba de 6 preguntas de tipo actitudinal, en las cuales el participante daba su opinión sobre el habla de los informantes específicos en una escala tipo Likert, con un puntaje mínimo de 1 y un máximo de 7.

Después de obtener los resultados de la prueba de actitudes lingüísticas y teniendo en consideración los resultados arrojados por la misma, el equipo de investigación del proyecto Fondecyt definió un puntaje mínimo de 5,5 en la escala tipo Likert para discriminar entre los hablantes "bien valorados" y "mal valorados" por los evaluadores. En virtud de esto, los resultados del test de actitudes lingüísticas fueron los que se presentan en la figura 1 .

Específicamente, la muestra de esta investigación estuvo compuesta por los cuatro informantes mejor valorados por ciudad, es decir, los cuatro informantes que obtuvieron las mejores calificaciones en el test de actitudes lingüísticas. De este modo, la muestra total quedó compuesta por 32 hablantes. Es importante aclarar que en el caso de la ciudad de Coyhaique solo tres informantes alcanzaron la categoría de "bien valorados" (5,5), de manera que el cuarto sujeto seleccionado fue aquel que obtuvo el cuarto mejor puntaje respecto de los tres informantes que fueron "bien valorados" por los evaluadores.

Por otra parte, es preciso también señalar que la elección de una muestra pequeña y filtra- 


\section{FIGURA 1}

Comparación entre hablantes bien valorados y mal valorados por ciudad

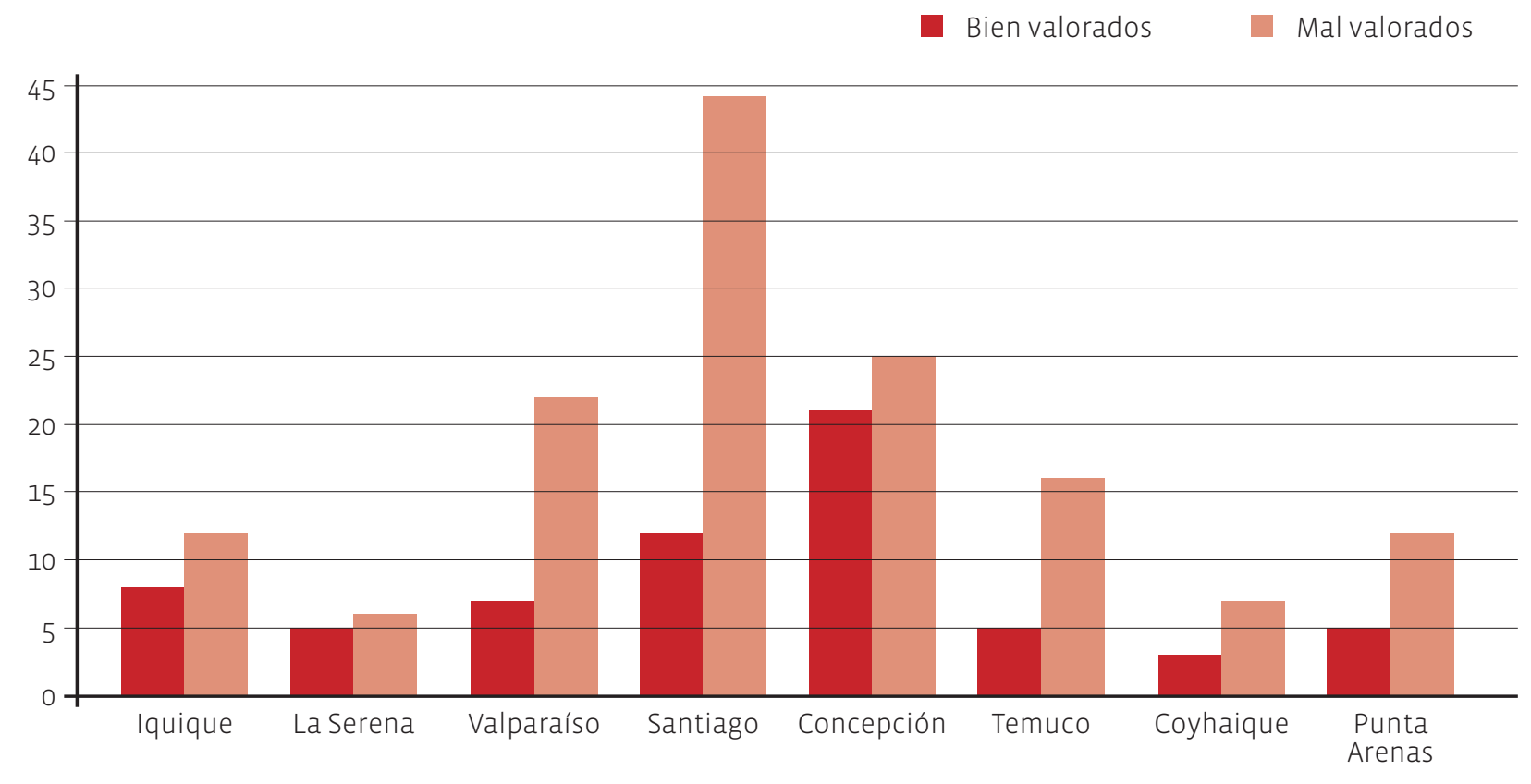

da por un test de actitudes lingüísticas se debió básicamente a dos factores. En cuanto al tamaño de la muestra, se privilegió analizar una mayor diversidad de ciudades que un número mayor de sujetos por ciudad. Esta decisión sobre el diseño de la investigación se tomó considerando el hecho de que existían estudios previos sobre ciudades o zonas específicas de Chile, como, por ejemplo, la ciudad de Valparaíso (Tassara y Duque, 1987; Valdivieso, Tassara, Magaña y Duque, 1988); la capital del país, Santiago (Valencia, 1995; Borland-Delorme, 2004); la ciudad de Concepción (Valdivieso y Magaña, 1987, 1988; Valdivieso, Tassara, Magaña y Duque, 1988); la ciudad de Valdivia (Cepeda, 1990, 1995; Cepeda y Poblete, 1993) y las zonas urbana y rural de la provincia de Ñuble (Soto-Barba, 2011). Sin embargo, no se encontraron estudios que se refirieran globalmente al fenómeno de la aspiración de /s/ codal en Chile continental, que es, por lo demás, un rasgo que parece ser característico y distintivo de la variedad dialectal del español de Chile.

Con respecto al filtro de la muestra por medio de la prueba de actitudes lingüísticas, convie- ne subrayar que la tradición de estudios sobre el fenómeno de /s/ codal en Chile se ha centrado en el habla llamada culta, así como también en el habla de los sectores socioculturales altos de la población. Por tanto, una submuestra del habla que los propios hablantes valoraron como "prestigiosa" permitía hacer comparaciones de los datos obtenidos con resultados de investigaciones previas, como, por ejemplo, los resultados de Tassara y Duque (1987), Valdivieso y Magaña (1987, 1988 y 1991), así como también, en menor medida, los resultados de Cepeda y Poblete (1993), Cepeda (1995) y Soto-Barba (2011).

En relación con lo anterior, es necesario dejar claro que este estudio no pretende describir el habla de cada una de las comunidades mencionadas ni tampoco llegar a conclusiones generalizantes sobre el habla de las mismas o sobre el habla chilena. Más bien, se buscó hacer una aproximación inicial al fenómeno de la variación alofónica de /s/ codal con informantes de ocho ciudades diferentes de Chile, con el fin de reactualizar el fenómeno en cuestión y contrastarlo con otras regiones de América Latina donde se 
ha observado también el fenómeno. Asimismo, se pretendió entregar un enfoque más amplio con respecto al fenómeno específico de variación alofónica de /s/ codal en Chile.

\section{Etapa 2. La entrevista}

Con la finalidad de identificar las realizaciones más frecuentes en la pronunciación del español de Chile, el proyecto Fondecyt № 1120886 registró visual y auditivamente 217 entrevistas. Las entrevistas fueron semidirigidas y tenían como objetivo que el informante conversara con naturalidad y espontaneidad. Por esta razón, los investigadores a cargo de realizar las entrevistas adoptaron el papel de mediador y participaron solo con los siguientes objetivos: propiciar modos discursivos deseados (descripción, narración, argumentación); mantener el tono conversacional de la charla; evitar silencios prolongados; alargar la actuación lingüística del informante; e introducir nuevos temas (López Morales, 1994). En cuanto a la estructura de las entrevistas, estas se dividieron en cinco partes: familiarización, descripción, argumentación, narración y lectura en voz alta.

\section{Etapa 3. Análisis del corpus}

Después de definida la toma de muestras, es necesario hacer la salvedad de que en esta investigación se trabajó solo con las partes de argumentación, narración y lectura en voz alta, ya que se consideró que son los modos discursivos que presentan la mayor cantidad de rasgos del discurso semiespontáneo (Labov, 1964).

En cuanto a los parámetros que se utilizaron en el análisis, conviene indicar que los cuatros autores de este artículo analizaron la muestra utilizando el método de audición clásico. Con respecto a las variantes analizadas, para el contexto fónico final de sílaba en interior de palabra, se analizaron las variantes fricativa glotal o aspirada sorda [h] y fricativa predorsoalveolar sorda [s]; en el caso del contexto fónico final de sílaba en final de palabra, se agregó a las dos variantes la elisión del segmento $(\varnothing)$.
En relación con el número de segmentos analizados, para la modalidad discursiva de entrevista semiespontánea, se analizó el fonema /s/ en 30 segmentos en posición final de sílaba interior de palabra y 30 segmentos en posición final de sílaba final de palabra. No se consideraron los siguientes contextos fónicos en el análisis: a) coda compleja (ej.:/eks.'tre.mo/,/trans.'por.tte/), y b) coalescencia del fonema /s/ en posición de coda y ataque (ej.: /las.'sa.las/). En el caso de la modalidad discursiva de lectura en voz alta, se analizaron 14 segmentos de /s/ en posición final de sílaba interior de palabra y 28 segmentos de /s/ codal en posición final de sílaba y final de palabra.

Por tanto, las 42 realizaciones de /s/ codal de cada informante de las ocho ciudades consideradas producidas en la modalidad discursiva lectura en voz alta y las 60 realizaciones de /s/ codal de cada informante en la modalidad discursiva de entrevista semiespontánea fueron analizadas fonéticamente recurriendo al método de audición clásico por los cuatro investigadores. Una vez que cada investigador realizó su análisis individual, los datos fueron triangulados, con el fin de contrastarlos y evaluar dudas y discrepancias en el análisis. Ahora bien, dado que el análisis fue de tipo auditivo clásico y el criterio para el análisis de los segmentos y su diferenciación fue acordado entre los mismos investigadores, se recurrió al software de análisis acústico Praat (versión 5.3.16) en caso de dudas y/o discrepancias. Cabe mencionar que la gran mayoría de las diferencias surgieron al diferenciar segmentos aspirados de elididos en el contexto fónico final de sílaba y final de palabra. Estas dudas se resolvieron recurriendo a representaciones oscilográficas y espectrográficas en el software antes mencionado y el criterio que se utilizó fue el siguiente: aspiración: presencia de señal; elisión: ausencia de señal.

\section{Etapa 4. Tabulación y análisis de los datos}

Una vez obtenidos los datos del análisis auditivo, estos se ingresaron en un primer momento en una planilla de cálculo del programa MS Excel (versión 10), con el fin de realizar un análisis 
de tipo descriptivo, que arrojó los resultados que se presentan en el apartado 4.1 y que se discuten en el apartado 5. Posteriormente, los datos se ingresaron en el programa de análisis estadístico SPSS Statistics (versión 19), mediante el cual se realizó la prueba $\chi 2$ de Pearson. Los datos entregados por el análisis estadístico se presentan en el apartado 4.2 (tabla 1) y se discuten, al igual que los resultados descriptivos, en el apartado 5.

\section{Resultados}

\subsection{Resultados generales de la distribu- ción de /s/ codal}

A continuación, se presentan los resultados descriptivos de la distribución de /s/ codal. Conviene mencionar que los resultados de los informantes de la muestra se presentarán agrupados de acuerdo con la ciudad de pertenencia de los mismos

En primer lugar, en la figura 2 se presentan los resultados de variación de / $\mathrm{s}$ / codal en la modalidad de lectura en voz alta, contexto fónico de interior de palabra final de sílaba.

Tal como se puede apreciar en esta figura, Ilama la atención que se manifestó una tenden- cia muy fuerte a la aspiración de /s/ en los informantes de las distintas ciudades del país. Es posible observar que los informantes de Valparaíso (100\%), lquique (94,6\%), Coyhaique (94,6\%) y Santiago $(92,9 \%)$ presentaron un mayor número de realizaciones de la variante alofónica [h]; en tanto, los informantes de Punta Arenas, La Serena, Concepción y Temuco, si bien también presentaron un alto porcentaje de realizaciones del alófono aspirado [h], entre $83,9 \%$ y $73,2 \%$, estos son menores. Por su parte, las producciones de [s] se observaron en los informantes de las ciudades en que se registró un porcentaje menor de aspiración. De cualquier modo, estas nunca superaron el 26,8\%.

En la figura 3 se puede apreciar que en el contexto final de sílaba interior de palabra, en la modalidad discursiva de entrevista, los informantes mostraron una tendencia constante a la aspiración del fonema/s/. En efecto, los informantes de cinco de las ciudades consideradas en la investigación (Iquique, La Serena, Santiago, Concepción y Coyhaique) no produjeron ninguna realización sibilante. Por su parte, en las otras tres ciudades (Valparaíso, Temuco y Punta Arenas) las realizaciones de la variante sibilante por parte de los informantes no superó un porcen-

\section{FIGURA 2}

Variación alofónica de /s/ codal en contexto interior de palabra y final de sílaba en lectura en voz alta

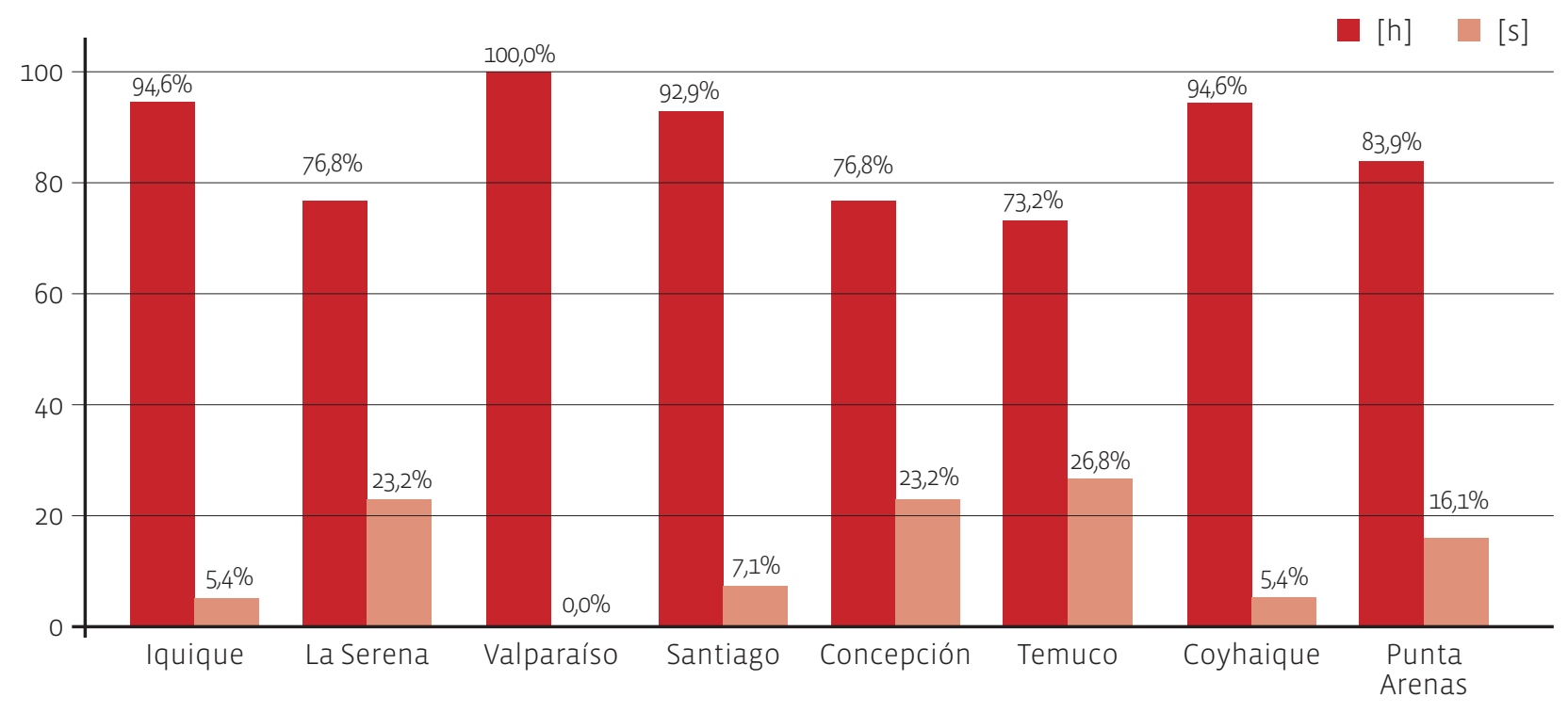


taje de $2,5 \%$. En otras palabras, de modo claro y sistemático, este contexto y esta modalidad dis- cursiva promovieron la producción de la variante [h] en los datos recolectados.

\section{FIGURA 3}

Variación alofónica de /s/ codal en contexto interior de palabra y final de sílaba en entrevista semiespontánea

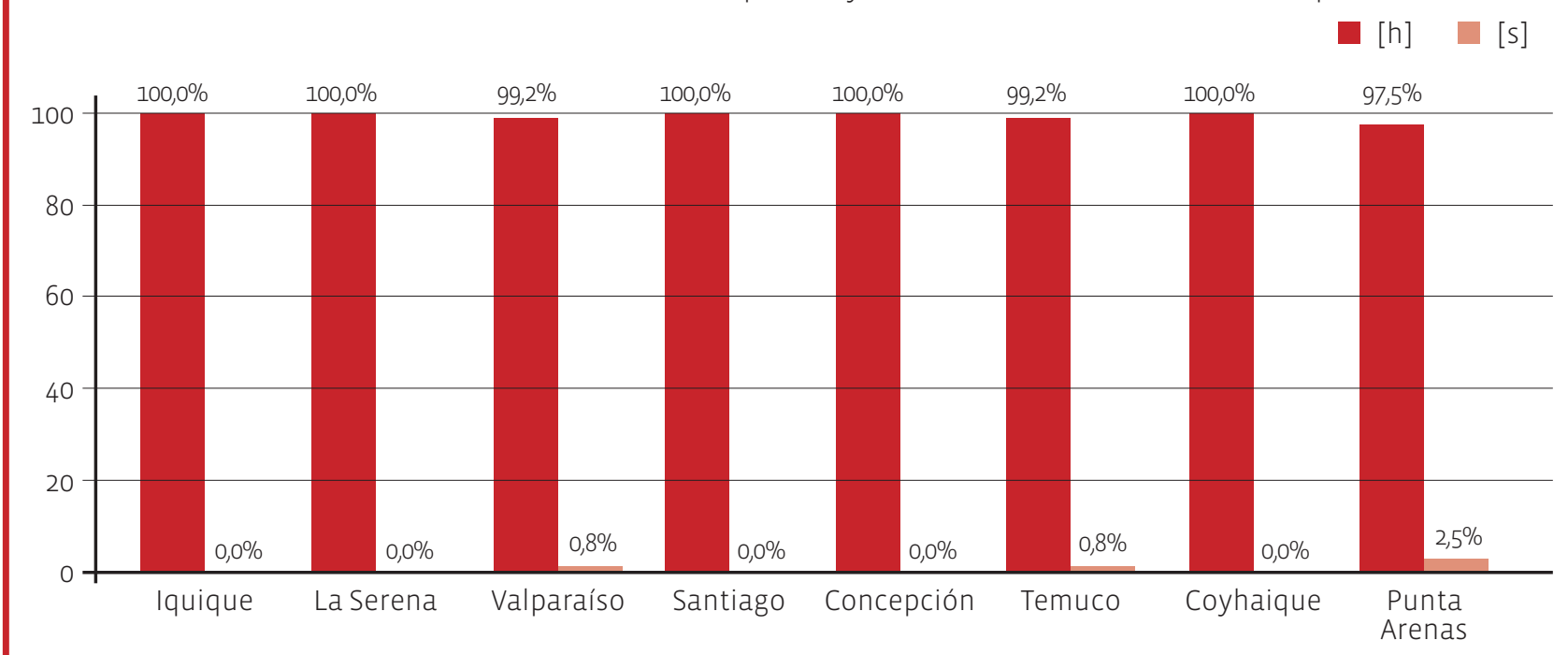

\section{FIGURA 4}

Variación alofónica de /s/ codal en contexto final de palabra y final de sílaba en lectura en voz alta

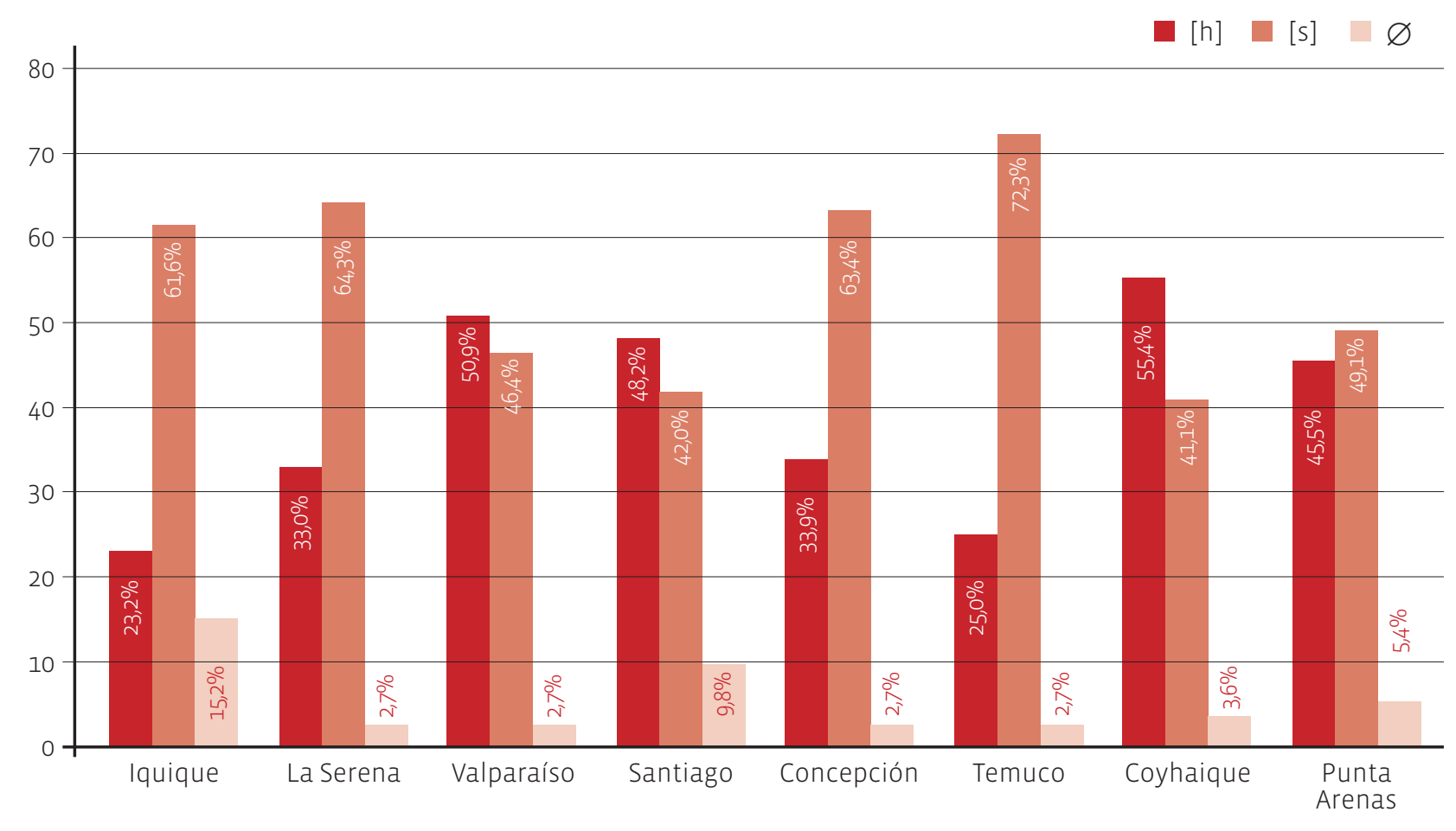


La figura 4 muestra tendencias distintas a las observadas en las figuras 2 y 3 . En este caso, la variante sibilante alcanzó porcentajes más altos que la variante aspirada en las realizaciones de los informantes de cinco ciudades: Iquique, La Serena, Concepción, Temuco y Punta Arenas (entre $72,3 \%$ y $49,1 \%$ ). Por su parte, los informantes de Valparaíso, Santiago y Coyhaique también presentaron porcentajes altos de realizaciones de la variante [s], aunque en menor frecuencia y sin superar a la producción de la variante aspirada. Además, en este contexto, fue posible apreciar la aparición con distintos porcentajes de la variante elidida $(\varnothing)$, sobre todo en los informantes de la ciudad de Iquique (15,2\%).

Por último, si bien la figura 5 muestra que los informantes de las ocho ciudades consideradas en la investigación realizan el fonema /s/ con la variante sibilante en porcentajes que oscilan entre $2,5 \%$ a $10,8 \%$ en este contexto y modalidad discursiva, es posible también constatar que la variante aspirada vuelve a presentar porcenta- jes muy altos en los datos de los informantes de cinco ciudades: Coyhaique (92,5\%), Valparaíso $(86,7 \%)$, Punta Arenas (80\%), Temuco $(75,8 \%)$ y Santiago (72,5\%). Por otra parte, aun cuando los informantes de las ciudades de Concepción, La Serena e Iquique presentan frecuencias menores de realización de la variante aspirada [h], de igual forma estos porcentajes son bastante altos $(67,5 \%, 65 \%$ y $52,5 \%)$ y superan a las otras dos variantes. Otro elemento importante en el contexto final de sílaba y final de palabra en la modalidad discursiva entrevista consistió en una frecuencia no menor de la variante elidida ( $\varnothing$ ).

Como se puede apreciar, los resultados presentados en las cuatro figuras anteriores revelan que en la modalidad discursiva de lectura en voz alta y en el contexto interior de palabra, final de sílaba (figura 2), se manifestó una tendencia a realizar la variante aspirada en los informantes de todas las ciudades estudiadas, aun cuando los informantes de La Serena, Concepción, Temuco y en menor medida los de Punta Arenas

\section{FIGURA 5}

Variación alofónica de /s/ codal en contexto final de palabra y final de sílaba en entrevista semiespontánea

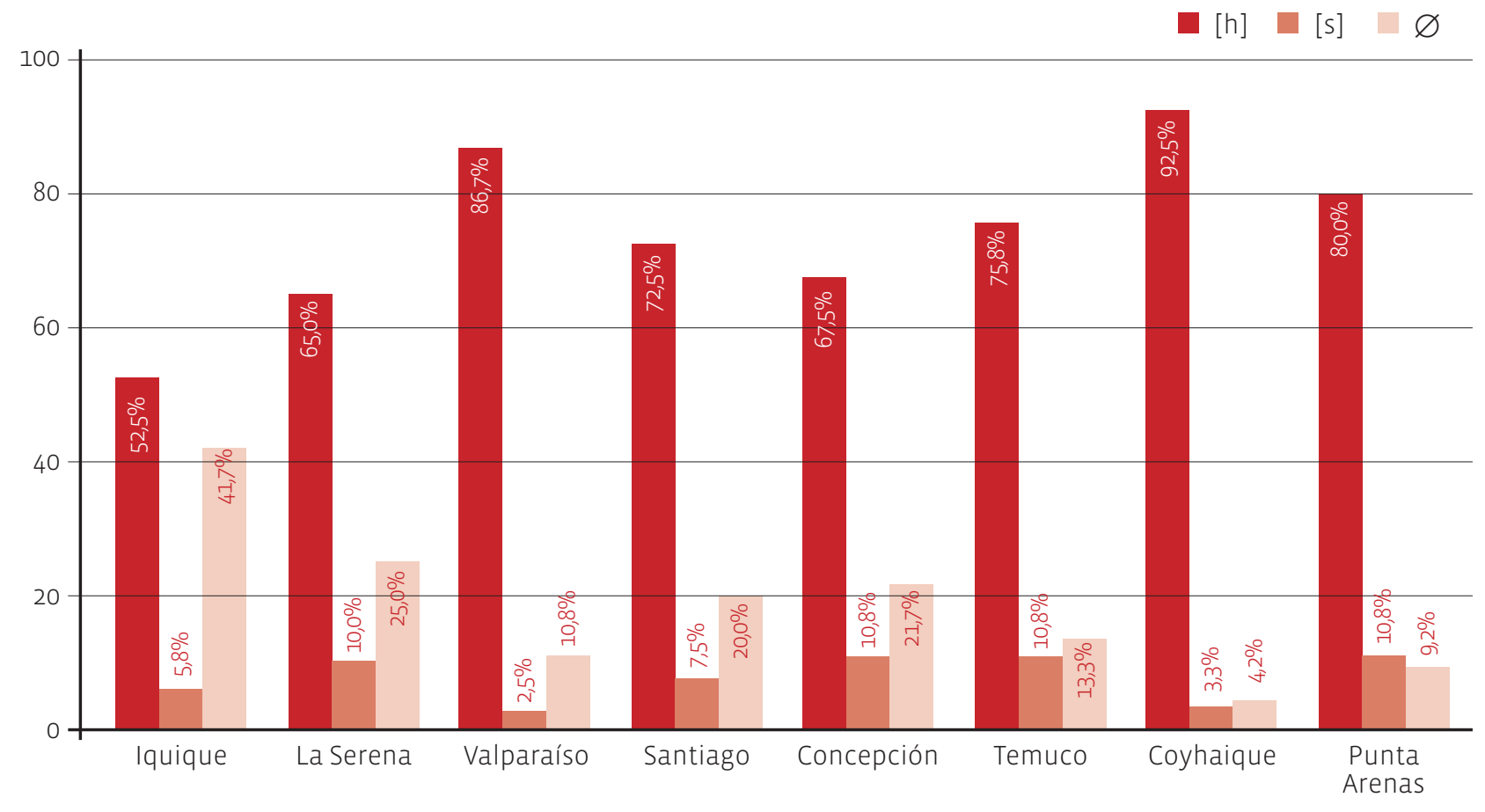


produjeron un número menor del realizaciones del alófono sibilante.

En cambio, en el contexto final de sílaba y final de palabra de la modalidad discursiva de lectura (figura 4), se observa una mayor distribución de las variantes. En primer lugar, cabe mencionar que esto se debe a que para este contexto las variantes posibles son tres en lugar de dos, pues, a diferencia de lo que ocurre en el contexto interior de palabra, el segmento puede también ser elidido. En segundo lugar, conviene destacar que en este contexto se observó una tendencia a la realización de la variante sibilante [s] por sobre la aspirada [h] en los informantes de las ciudades de Iquique, La Serena, Concepción, Temuco y Punta Arenas; ahora bien, los informantes de las ciudades de Valparaíso, Santiago y Coyhaique realizaron con más frecuencia la variante aspirada [h], aun cuando también se constató una alta frecuencia de la variante [s]. Asimismo, es importante mencionar que en este contexto los porcentajes de elisión en la muestra son bajos en relación con el mismo contexto en la otra modalidad discursiva, tendencia que se discutirá en el apartado 5.

En la modalidad discursiva de entrevista semiespontánea y en el contexto interior de palabra y final de sílaba (figura 3), los resultados indican que la tendencia general entre los informantes fue a realizar la variante aspirada. Esto se puede apreciar, ya que los porcentajes de aspiración fueron altísimos en los datos de los informantes de todas las ciudades estudiadas y oscilaron entre un 98\% de aspiración en los informantes de Punta Arenas a un $\mathbf{1 0 0 \%}$ en los informantes de las ciudades de Iquique, Santiago, Concepción y Coyhaique.

En cuanto al contexto final de sílaba y final palabra en la modalidad discursiva de entrevista semiespontánea (figura 5), si bien se observó una alta frecuencia de la variante aspirada, que por lo demás superó en frecuencia a las otras variantes, se constató también una mayor distribución de los alófonos de /s/ codal en este contexto y en esta modalidad discursiva en los datos de la muestra. Por ejemplo, la variante elidida $(\varnothing)$ presentó una frecuencia de realización importante entre los informantes de las ciudades de Iquique, La Serena, Santiago y Concepción. Así también, y a diferencia del contexto final de palabra en la modalidad discursiva de lectura en voz alta, en la modalidad discursiva de entrevista y el contexto final de palabra se observaron muy pocas realizaciones de la variante sibilante [s] por parte de los informantes.

A modo de resumen, y en relación con los gráficos anteriormente presentados, es posible señalar que la variante que presentó una mayor frecuencia de realizaciones en la muestra analizada fue la variante aspirada. Conviene mencionar que en el caso del contexto interior de palabra final de sílaba, en la modalidad de entrevista semiespontánea, el porcentaje de realizaciones de [h] llegó inclusive al 100\% en los informantes de cinco ciudades (Iquique, La Serena, Santiago, Concepción y Coyhaique). Por otra parte, en un contexto que intuitivamente podría ser considerado como más conservador, como el contexto interior de palabra y final de sílaba en la modalidad discursiva de lectura en voz alta, se observaron también informantes con un porcentaje de realizaciones de la variante [h] sobre un 90\%, como los informantes de Iquique, Santiago y Coyhaique, e, inclusive, los informantes de Valparaíso produjeron en su totalidad realizaciones aspiradas. Además, es importante señalar que, si bien en el contexto final de palabra en lectura en voz alta se observó una frecuencia de la variante sibilante [s] que superó a la variante aspirada en los datos de los informantes de seis de las ocho ciudades de la muestra, los informantes de Iquique, que fueron los que menos realizaron el alófono aspirado en este contexto fónico y modalidad, presentaron un $23,2 \%$ de realizaciones del alófono aspirado, y los informantes de Coyhaique, que fueron los que más produjeron el alófono [h] en este contexto fónico y modalidad discursiva, presentaron un 55,4\% de segmentos aspirados. 


\subsection{Distribución general de la variable dependiente estudiada}

A continuación, se presentan los resultados de los análisis estadísticos realizados con el fin de observar la distribución de la variable dependiente estudiada y el posible efecto que las variables independientes tienen en la distribución de la variación del fonema /s/ en posición codal. Cabe destacar que los resultados del análisis estadístico solo se comentarán brevemente, ya que el grueso del análisis, es decir, las conjeturas que se pueden hacer con respecto a estos datos, se formularán en el apartado "Discusión de resultados".

Para realizar este análisis, fue necesario observar inicialmente la relación entre todas las variables estudiadas, con el fin de comprobar o rechazar la hipótesis nula. Por esta razón, en el anexo 1 , se presenta una tabla de contingencia de análisis general, la cual combina todas las variables estudiadas (fonema/s/ en posición codal, ciudad específica, modalidad discursiva y contexto fónico). Esta tabla permite ver un panorama general de la distribución de las frecuencias esperadas versus las observadas.

En relación con los resultados de la tabla panorámica (véase anexo 1), es posible señalar que se observan valores residuales diferentes a los esperados para la distribución de $\chi 2$ en la mayoría de las casillas; es decir, en la mayoría de los casos, la hipótesis nula se rechaza y se observan diferencias en la distribución de los datos. Ahora bien, para comprobar o rechazar las hipótesis alternativas, se realizó igualmente la prueba $\chi 2$ con el fin de medir el efecto de las siguientes variables en la distribución de las variantes de la variable dependiente /s/ en posición codal: a) variación de /s/ codal y ciudad; b) variación de /s/ codal y modalidad discursiva; c) variación de /s/ codal y contexto fónico. En la tabla 1 , se presentan los valores de las pruebas de $\chi 2$ para los cruces de variables antes mencionados.

\section{TABLA 1}

Resultados de pruebas de $\chi 2$

\begin{tabular}{|c|c|c|}
\hline PRUEBAS DE $\chi^{2}$ & VALOR DE $\chi 2$ & VALOR DE P \\
\hline Variación de /s/ codal y ciudad & $\chi^{2}(14, N=3264)=144.067^{a}$ & $* * p<.001$ \\
\hline $\begin{array}{c}\text { Variación de /s/ codal y modalidad } \\
\text { discursiva }\end{array}$ & $\chi^{2}(2, N=3264)=702.691^{a}$ & $* * p<.001$ \\
\hline $\begin{array}{l}\text { Variación de /s/ codal y contexto } \\
\text { fónico }\end{array}$ & $\chi_{2}(2, N=3264)=600.266^{a}$ & $* * p<.001$ \\
\hline \multirow{2}{*}{$\begin{array}{l}\text { Variación de /s/ codal, contexto } \\
\text { fónico y modalidad discursiva }\end{array}$} & $\begin{array}{l}\text { Contexto interior de palabra: } \\
\qquad x^{2}(1, N=1408)=117.242^{b}\end{array}$ & ${ }^{* *}$ Contexto interior de palabra: $p<.001$ \\
\hline & $\begin{array}{l}\text { Contexto final de palabra: } \\
x^{2}(2, N=1856)=497.916^{d}\end{array}$ & **Contexto final de palabra: $p<.001$ \\
\hline
\end{tabular}

Tal como se puede observar en la tabla 1 , los valores de p son significativos para todas las pruebas de $x 2$ realizadas; es decir, como ya se mencionaba anteriormente, en todas las pruebas se rechaza la hipótesis nula y se observa que hay diferencias entre los valores esperados y los observados en la prueba de $\chi 2$ para la relación entre las variables /s/ codal y ciudad; /s/ codal y modalidad discursiva; /s/ codal y contexto fónico; y /s/ codal, contexto fónico y modalidad discursiva. A continuación, en el apartado 5, se discuten los resultados de estas pruebas. 


\section{Discusión de resultados}

\subsection{Variación diatópica y variación de /s/ codal}

Al respecto de los resultados anteriormente presentados, es plausible señalar lo siguiente en relación con la distribución de las variantes alofónicas de la variable dependiente /s/ codal. En relación con la variante [s], se observa un efecto de la variable independiente ciudad en la mayoría de los datos de los informantes de cada ciudad, a excepción de los informantes de Punta Arenas e Iquique, ciudades en las cuales los valores observados de la muestra de informantes no superaron significativamente a los esperados. En este sentido, es posible dividir la muestra de las ciudades estudiadas en tres subgrupos: a) ciudades con una muestra que presenta una frecuencia observada por sobre la esperada: La Serena, Concepción y Temuco; b) ciudades con una muestra que presenta una frecuencia observada por debajo de la esperada: Valparaíso, Santiago y Coyhaique; y c) ciudades con una muestra que presenta una frecuencia observada y esperada que no tiene una relación significativa: Iquique y Punta Arenas. Por tanto, si se aprecian los resultados observados y los esperados, no es posible señalar que exista un comportamiento sistemático entre los informantes de las ciudades de la muestra (a excepción tal vez de lo que sucede en los dos extremos del país) respecto de la realización de la variante sibilante [s], pues se observa que los fenómenos de variación no tienen un patrón geográfico consistente.

Con relación a la variante [h], la prueba de $\chi^{2}$ evidenció que los informantes de seis ciudades de la muestra presentan frecuencias por sobre o por debajo de lo esperado y los datos de los informantes de dos ciudades muestran una relación no significativa entre la frecuencia esperada y la observada. Por lo mismo, es también posible dividir la muestra de las ciudades estudiadas en tres subgrupos: a) ciudades con una muestra que presenta una frecuencia observada por sobre la esperada: Valparaíso y Coyhaique; b) ciudades con una muestra que presenta una frecuencia observada por debajo de la esperada: Iquique, La Serena, Concepción y Temuco; y c) ciudades con una muestra que tiene frecuencias observadas y esperadas que no tiene una relación significativa: Santiago y Punta Arenas. Nuevamente, si contrastamos los resultados observados y los esperados, no es posible señalar que exista un comportamiento sistemático entre los subgrupos de la muestra, a excepción tal vez de la relativa proximidad entre ciudades como Concepción y Temuco, que forman parte de las ciudades que tienen una frecuencia menor a la esperada; sin embargo, cabe destacar que este fenómeno también se da en Iquique y La Serena, ciudades que se encuentran a 1.084 kilómetros de distancia.

En cuanto a la variante elidida ( $\varnothing$ ), es también posible dividir la muestra de las ciudades estudiadas en tres subgrupos: a) ciudades que presentan una frecuencia observada por sobre lo esperado: Iquique; b) ciudades que presentan una frecuencia observada por debajo de lo esperado: Valparaíso, Coyhaique y Punta Arenas; y c) ciudades que presentan frecuencias observadas y esperadas que no tienen una relación significativa: La Serena, Santiago, Concepción y Temuco. Al igual que para las variantes anteriores, si contrastamos los resultados observados y los esperados, no es posible señalar que exista un comportamiento sistemático entre las distintas ciudades de la muestra, ya que la mayoría de las ciudades que conforman los distintos grupos se encuentran bastante alejadas entre sí.

Por lo tanto, de acuerdo con los datos obtenidos por medio de la prueba de $\chi 2$ acerca de la frecuencia de las distintas variantes de /s/ codal en los informantes de las ocho ciudades de la muestra, y aun cuando se observan diferencias entre las frecuencias esperadas y las observadas, no es posible señalar que existe un comportamiento sistemático respecto de la variación de/s/ codal por factores de tipo geográfico en los resultados obtenidos. Esto se debe a que, si pensamos que Chile continental tiene 
una extensión aproximada de 4.300 kilómetros, se hace evidente que no es posible aducir la variación de /s/ codal a factores diatópicos cuando existen fenómenos similares en ciudades tan alejadas geográficamente como Valparaíso y Coyhaique con respecto a la elisión o como La Serena y Temuco con respecto a la aspiración. Es decir, no se observa un comportamiento claro por zona geográfica en los informantes de esta muestra en particular, a diferencia de lo observado en otras regiones de Hispanoamérica (Samper, 2001).

\subsection{Variación de /s/ codal, modalidad discursiva y contexto fónico}

Respecto de la variación de /s/ codal y la modalidad discursiva, se hace evidente, tanto en los gráficos descriptivos como en la prueba de $\chi 2$, que ciertas modalidades discursivas propiciaron la realización de una variante específica de /s/ codal. En este sentido, se observó que la modalidad discursiva de lectura propiciaba la realización de la variante sibilante [s] e, inversamente, la modalidad de entrevista semiespontánea propiciaba la variante aspirada [h], tal como señaIaron anteriormente Valdivieso y Magaña (1988), Valdivieso, Tassara, Magaña y Duque (1988), CidHazard (2003) y Pérez (2007). Así también, la modalidad discursiva de entrevista semiespontánea propició la realización de la variante elidida $(\varnothing)$ y la modalidad discursiva de lectura la desfavoreció, fenómeno que también fue consignado por Pérez (2007) en su investigación.

En cuanto a la distribución de acuerdo con el contexto fónico de la variante [s], es posible señalar que se observaron diferencias entre los contextos interior y final de palabra. Los datos de la prueba de $x 2$ indicaron que el contexto final de palabra propiciaba más la realización de la sibilante [s], ya que la frecuencia observada fue de 22,1 en oposición a una frecuencia observada de 10,8 en posición interior; así también, se apreció que tan solo en el contexto final de palabra el número de realizaciones de la variante sibilante [s] superó al número de realizaciones de la variante aspirada [h]. En cambio, en el contexto interior de palabra, predominó la variante aspirada [h] por sobre la variante sibilante [s]. Dicho de otro modo, el contexto final de palabra y la modalidad discursiva de lectura fueron factores condicionantes para la realización de la variante sibilante [s] en la muestra estudiada.

Con relación a la variante [h], se observó que tanto el contexto interior como final de palabra, en la modalidad discursiva de entrevista, propiciaron la realización del alófono aspirado, puesto que el número de realizaciones de [h] superó ampliamente a las otras variantes en ambos contextos fónicos de la muestra. Esta evidencia de la alta frecuencia de realizaciones del alófono [h] en el contexto de entrevista semiespontánea en ambos contextos fónicos había sido también ya consignada por Soto-Barba (2011) en su estudio acerca de la provincia de Ñuble. Igualmente, si tomamos en cuenta lo planteado por Finegan y Bieber (1994) con respecto a la economía de ciertos registros, no es sorprendente que se haya observado una alta frecuencia de aspiración en la entrevista semiespontánea.

\subsection{El fenómeno de la aspiración y su permeabilidad en los distintos contex- tos y modos discursivos}

Es posible señalar que en los datos anteriormente entregados se observó un avance en el debilitamiento del fonema/s/ en posición codal en la modalidad discursiva de lectura en voz alta. Como hemos ya descrito anteriormente, los datos indican que el fenómeno traspasó la modalidad discursiva de entrevista semiespontánea - una modalidad que clásicamente había sido descrita como un ambiente favorable para la variante aspirada [h] en la literatura expuesta acerca del español de Chile- y se posicionó fuertemente también en la modalidad de lectura en voz alta, siendo inclusive más prominente que la variante sibilante [s] en el contexto interior de palabra en la muestra. 
Este avance en el proceso de debilitamiento de /s/ codal en el español de Chile ya había sido observado por Cepeda (1990) en Valdivia, quien constató una mayor tendencia al debilitamiento del fonema/s/ en posición codal en los informantes más jóvenes de la muestra. Por tanto, es posible aseverar que, si bien la literatura ya informaba acerca de la marcada tendencia a realizar la variante aspirada [h] en la modalidad discursiva de entrevista semiespontánea en el español de Chile, los datos de esta investigación aportan nueva información sobre el avance del fenómeno, ya que se registró también una alta frecuencia de la variante aspirada en contextos formales.

Por otra parte, si se confirma este avance del fenómeno de la aspiración con una muestra aún mayor, se podría también reafirmar el lugar de Chile en la categorización propuesta por Samper (2001) sobre la variación de /s/ codal y los dialectos del español. Samper (2001) caracterizó al español de Chile como un dialecto intermedio, ya que la tendencia general en Chile es a realizar la variante aspirada para el fonema/s/ en posición codal, y los datos de esta investigación así también lo respaldan.

\subsection{La estabilidad del fenómeno de la elisión}

Como se puede observar en los apartados, la variante elidida $(\varnothing)$ tiene un porcentaje de $9,16 \%$ de los casos en la modalidad discursiva de entrevista semiespontánea y un 3,72\% en lectura. En relación con esto, cabe señalar que se observa una relativa estabilidad del fenómeno de la elisión en la muestra, ya que los datos arrojados por la investigación no distan significativamente de los porcentajes de realización de la variante elidida $(\varnothing)$ entregados por Valdivieso y Magaña (1987) y Tassara y Duque (1987) para lectura en Concepción y Valparaíso, respectivamente; así también, son similares a lo informado por Cepeda (1990) para Valdivia en el caso de la entrevista semiespontánea.

\section{Conclusiones}

En relación con la variable diatópica, los datos sugieren que la variación del fonema/s/ en posición codal no presentó un comportamiento sistemático en las ocho ciudades de la muestra. En este sentido, se constató una variación que oscilaba entre dos extremos, pero que se mostró "estable" en términos de reproducir ciertos fenómenos como la aspiración, por ejemplo. Con todo, se hace necesario mirar con más detención y hacer una investigación en el futuro con un tamaño muestral mayor, ya que los datos tampoco permitieron rechazar la hipótesis alternativa de variación diatópica.

Con respecto al contexto fónico, se observó que el contexto final de palabra incidía en la realización de la variante [s] en ciertas modalidades discursivas. Ahora bien, en el caso del alófono aspirado, pareciera ser que el contexto, ya sea interior o final de palabra, no incidió de manera significativa en los datos de la muestra, en tanto este alófono se observó como un fenómeno que trascendió contextos e, inclusive, pareciera ser que también ha llegado a trascender las modalidades discursivas semiformales, si se considera la frecuencia no menor de este alófono en la modalidad discursiva de entrevista. Respecto de la variante elidida $(\varnothing)$, es posible también afirmar que se observó estabilidad en la frecuencia de ocurrencias de esta variante en la muestra.

En cuanto a la variable de modalidad discursiva, se observó que incide en la variación de los distintos alófonos de /s/ codal en los informantes de la muestra. Los resultados indicaron que la modalidad discursiva de lectura en voz alta propiciaba la aparición de la variante sibilante [s] en desmedro de la variante [h] e, inversamente, la modalidad discursiva de entrevista semiespontánea generaba un aumento en la frecuencia de la variante aspirada [h], así como también se constató que esta modalidad propiciaba la aparición de la variante elidida $(\varnothing)$.

Además de estas observaciones en relación con las tres variables independientes analiza- 
das, surgieron también otros hallazgos interesantes a la luz de los resultados de esta investigación. El primero de ellos guarda relación con la permeabilidad en la muestra del fenómeno de la aspiración. Si bien la frecuencia de la variante aspirada [h] en los registros informales del español de Chile ya había sido consignada en la literatura (Wigdorsky, 1978; Tassara y Duque, 1987; Valdivieso y Magaña, 1987, 1988; Valdivieso, Tassara, Magaña y Duque, 1988; Cepeda, 1990, 1995; Valencia, 1995; Pérez, 2007, y Soto-Barba, 2011), los resultados de esta investigación indican que la variante [h] se estaría volviendo incluso más frecuente que la variante [s] no tan sólo en los registros informales, sino también en las modalidades discursivas más formales, lo cual se opone a lo señalado anteriormente por Valdivieso y Magaña (1987) y Tassara y Duque (1987).

Un segundo punto que resulta de interés es la relativa estabilidad de la variante elidida $(\varnothing)$ en la muestra estudiada. Al analizar los datos, no se apreció un avance de esta variante alofónica, pese a lo que se podría creer intuitivamente, en tanto el español de Chile pareciera tender al debilitamiento. En este mismo sentido, no sería posible entonces aportar datos para señalar que el español de Chile es un dialecto avanzado, ya que no se observó una tendencia a la elisión en la muestra, como sí se ha observado en República Dominicana (Alba, 1982; Núñez Cedeño, 1980, en Lipski, 1994: 239) o Ciudad de Panamá (Cedergreen, 1978). Más bien, se apreció una tendencia a realizar la variante aspirada en los informantes y, por lo tanto, los datos respaldan lo propuesto por Samper (2001) acerca del español de Chile.

\section{Bibliografía citada}

Alarcos Llorach, Emilio, 1961: Fonología española, Madrid: Gredos.

Cenergreen, Henrietta, 1973: Interplay of social and linguistic factors in Panama. Tesis inédita de doctorado, Universidad de Cornell, Ítaca, Estados Unidos.
Cedergreen, Henrietta,1978: "En torno a la variación de la /s/ final de sílaba en Panamá: análisis cuantitativo" en Humberto López Morales (ed.): Corrientes actuales en la dialectología del Caribe hispánico, Río Piedras: Universidad de Puerto Rico, 80-103.

CepedA, Gladys, 1990: "La variación de /S/ en Valdivia: sexo y edad”, Hispania 73 (1) [http:// www.cervantesvirtual.com/obra-visor/hispania--5/html/02754dde-82b2-11df-acc7002185ce6064_62.html, fecha de consulta: 4 de mayo de 2014].

CepedA, Gladys,1991: Las consonantes de Valdivia. Valdivia: Fondecyt, Universidad Austral de Chile. CepedA, Gladys, 1995: "Retention and deletion of word-final /s/ in Valdivian Spanish (Chile)", Hispanic Linguistics 6/7, 329-353.

Cepeda, Gladys y María Teresa Poblete, 1993: "Retención y elisión de $/ \beta /$ y $/ \delta /$ en sufijos y morfemas radicales. Condicionamiento morfofonológico y sociolingüístico", Estudios Filológicos 28, 87-96.

Cid-Hazard, Susana, 2003: "Variación de estilo en relación a la variable fonológica/s/ en el español de Santiago de Chile", Southwest Journal of Linguistics 22(2), 13-43 [http://www.questia.com/ library/journal/1G1-115566985/variacion-de-estilo-en-relacion-a-la-variable-fonologica, fecha de consulta: 20 de septiembre de 2014].

Finegan, Edward y Douglas Biber, 1994: "Register and social dialect variation: An integrated approach", en Sociolinguistic perspectives on register, New York: Oxford University Press, 315-347.

Labov, William, 1964: "Phonological Correlates of Social Stratification", American Anthropologist 66(6), 164-176 [http://dx.doi.org/10.1525/ aa.1964.66.suppl_3.02a00120, fecha de consulta: 2 de agosto de 2014]

Lagos, Daniel y Selma Olivera, 1988: "Algunas características del español hablado por los escolares mapuches de la comuna de Victoria", Estudios Filológicos 23, 69-87. 
LIPSKI, John, 1983: "Reducción de /s/ en el español de Honduras", Nueva Revista de Filología Hispánica 32(2), 272-288 [http://www.jstor.org/sta ble/40298564, fecha de consulta: 5 de agosto de 2014]

LIPSKI, John, 1994: Latin American Spanish, Nueva York: Longman.

López Morales, Humberto, 1994: Métodos de Investigación Lingüística, Salamanca: Colegio de España.

Oroz, Rodolfo, 1966: La lengua castellana en Chile, Santiago, Chile: Editorial Universitaria.

Ortiz-LiRa, Héctor y Eugenia SaAvedra-Valenzuela, 2003: La fonética en Chile. Bibliografía analítica 1829-2000, Santiago, Chile: Phoné-Libros.

Pérez, Hernán Emilio, 2007: "Estudio de la variación estilística del fonema /s/ en posición implosiva en el habla de los noticieros de la televisión chilena", R.L.A. Revista de lingüística teórica y aplicada 45(1), 101-115 [http://www.scielo.cl/scielo.php?script=sci_ arttext\&pid=S0718-48832007000100007\&lng=es\& tlng=es, fecha de consulta: 08 de junio de 2014]

Ramírez, Carlos, 1971: "Forma lingüística del habla rural de la provincia de Cautín (Chile)", Estudios Filológicos 7, 197-250.

SAMPER, José Antonio, 2001: "La variación fonológica: Ios estudios hispánicos sobre -/s/ implosiva", ponencia presentada en el Congreso de Valladolid. Unidad y diversidad del español. [http:// cvc.cervantes.es/obref/congresos/valladolid/ ponencias/unidad_diversidad_del_espanol/ I_la_norma_hispanica/samper_j.htm, fecha de consulta: 10 de febrero de 2014].

Sото-BARBA, Jaime, 2011: "Variación consonántica en el habla urbana y rural de la provincia de Ñuble", R.L.A., Revista de lingüística teórica y aplicada 49 (2), 111-127 [http://www.scielo. $\mathrm{cl} /$ scielo.php?script=sci_arttext\&pid=S0718- 48832011000200006\&lng=es\&tlng=en, fecha de consulta: 08 de junio de 2014].

TASSARA, Gilda y Carlos Duque, 1987: "Variación del segmento /s/ en el español culto de Valparaíso" en VII Seminario de investigación y enseñanza de la lingüística de la Sociedad Chilena de Lingüística, Valparaíso: Universidad Católica de Valparaíso, 309-324.

Valdivieso, Humberto y Juanita Magaña, 1987: "Variación del segmento /s/ en el español culto de Concepción" en VII Seminario de investigación y enseñanza de la lingüística de la Sociedad Chilena de Lingüística, Valparaíso: Universidad Católica de Valparaíso, 325-335.

Valdivieso, Humberto y Juanita Magaña, 1988: "Variación lingüística de /s/ implosiva en Concepción", R.L.A., Revista de lingüística teórica y aplicada 26, 91-103.

Valdivieso, Humberto y Juanita Magaña, 1991: "Variación fonética de/s/en el habla espontánea”, R.L.A., Revista de Lingüística Teórica y Aplicada 29, 97113 [http://www.scielo.cl/scielo.php?script=sci_ arttext\&pid=S0718-48832008000100002, fecha de consulta: 8 de junio de 2014].

Valdivieso, Humberto, Gilda Tassara, Juanita MAgaña y Carlos Duque, 1988: "Le /s/ implosif dans l'espagnol de Concepción et de Valparaíso (Chili)", La Linguistique 24, (2), 131-141.

Valencia, Alba, 1993-94: "Realizaciones de /S/, /ĉ/y /ĵ/ en el habla adolescente", Nueva Revista del Pacífico 38/39, 159-180.

Wagner, Claudio, 1967: "El español de Valdivia: fonética y léxico", Estudios Filológicos 3, 246-302. Wagner, Claudio, 2004: "El atlas lingüístico y etnográfico de Chile. Localidades y cuestionario", Estudios Filológicos 39, 83-120.

WygDoRsky, Leopoldo, 1978: "Realización de algunos fonemas consonánticos en el castellano de Santiago. Informe preliminar", R.L.A., Revista de lingüística teórica y aplicada 16, 53-60. 


\section{Anexos}

TABLA 2

Tabla de contingencia del análisis de las variables /s/ codal, ciudad, modalidad discursiva y contexto fónico

\begin{tabular}{|c|c|c|c|c|c|c|c|c|}
\hline \multirow{2}{*}{ CIUDAD } & \multirow{2}{*}{\multicolumn{4}{|c|}{ MODALIDAD DISCURSIVA }} & \multicolumn{3}{|c|}{ /S/ } & \multirow{3}{*}{$\begin{array}{l}\text { TOTAL } \\
120\end{array}$} \\
\hline & & & & & [S] & {$[\mathrm{H}]$} & $\varnothing$ & \\
\hline \multirow{15}{*}{$\begin{array}{l}\text { U } \\
\stackrel{Ð}{\supset} \\
\stackrel{0}{\varrho}\end{array}$} & \multirow{5}{*}{ Entrevista } & \multirow{4}{*}{$\begin{array}{l}\text { Contexto } \\
\text { fónico }\end{array}$} & \multirow{2}{*}{ Interior } & Recuento & 0 & 120 & 0 & \\
\hline & & & & Residuos corregidos & -2.7 & 8.6 & -7.9 & \\
\hline & & & \multirow{2}{*}{ Final } & Recuento & 7 & 63 & 50 & 120 \\
\hline & & & & & 2.7 & -8.6 & 7.9 & \\
\hline & & \multicolumn{2}{|l|}{ Total } & Recuento & 7 & 183 & 50 & 240 \\
\hline & \multirow{5}{*}{ Lectura } & \multirow{4}{*}{$\begin{array}{l}\text { Contexto } \\
\text { fónico }\end{array}$} & \multirow{2}{*}{ Interior } & Recuento & 3 & 53 & 0 & 56 \\
\hline & & & & Residuos corregidos & -6.9 & 8.7 & -3.1 & \\
\hline & & & \multirow{2}{*}{ Final } & Recuento & 69 & 26 & 17 & 112 \\
\hline & & & & Residuos corregidos & 6.9 & -8.7 & 3.1 & \\
\hline & & \multicolumn{2}{|l|}{ Total } & Recuento & 72 & 79 & 17 & 168 \\
\hline & \multirow{5}{*}{ Total } & \multirow{4}{*}{$\begin{array}{l}\text { Contexto } \\
\text { fónico }\end{array}$} & \multirow{2}{*}{ Interior } & Recuento & 3 & 173 & 0 & 176 \\
\hline & & & & Residuos corregidos & -7.9 & 12.5 & -7.8 & \\
\hline & & & \multirow{2}{*}{ Final } & Recuento & 76 & 89 & 67 & 232 \\
\hline & & & & Residuos corregidos & 7.9 & -12.5 & 7.8 & \\
\hline & & \multicolumn{2}{|l|}{ Total } & Recuento & 79 & 262 & 67 & 408 \\
\hline \multirow{15}{*}{ 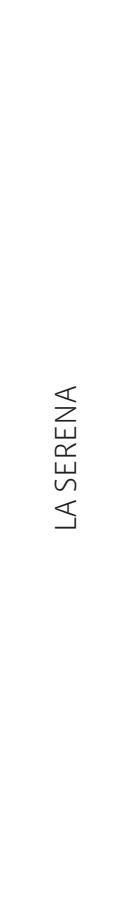 } & \multirow{5}{*}{ Entrevista } & \multirow{4}{*}{$\begin{array}{l}\text { Contexto } \\
\text { fónico }\end{array}$} & \multirow{2}{*}{ Interior } & Recuento & 0 & 119 & 1 & 120 \\
\hline & & & & Residuos corregidos & -3.6 & 6.9 & -5.6 & \\
\hline & & & \multirow{2}{*}{ Final } & Recuento & 12 & 78 & 30 & 120 \\
\hline & & & & Residuos corregidos & 3.6 & -6.9 & 5.6 & \\
\hline & & \multicolumn{2}{|l|}{ Total } & Recuento & 12 & 197 & 31 & 240 \\
\hline & \multirow{5}{*}{ Lectura } & \multirow{4}{*}{$\begin{array}{l}\text { Contexto } \\
\text { fónico }\end{array}$} & \multirow{2}{*}{ Interior } & Recuento & 14 & 42 & 0 & 56 \\
\hline & & & & Residuos corregidos & -4.8 & 5.1 & -1.2 & \\
\hline & & & $\ulcorner$ i & Recuento & 72 & 37 & 3 & 112 \\
\hline & & & & Residuos corregidos & 4.8 & -5.1 & 1.2 & \\
\hline & & Total & & Recuento & 86 & 79 & 3 & 168 \\
\hline & & & $\ln t$ & Recuento & 14 & 161 & 1 & 176 \\
\hline & & Contexto & & Residuos corregidos & -6.6 & 9.0 & -4.9 & \\
\hline & Total & fónico & & Recuento & 84 & 115 & 33 & 232 \\
\hline & & & & Residuos corregidos & 6.6 & -9.0 & 4.9 & \\
\hline & & Total & & Recuento & 98 & 276 & 34 & 408 \\
\hline
\end{tabular}




\begin{tabular}{|c|c|c|c|c|c|c|c|c|}
\hline \multirow{15}{*}{ 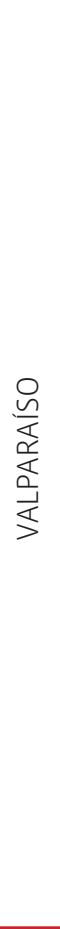 } & \multirow{5}{*}{ Entrevista } & \multirow{4}{*}{$\begin{array}{l}\text { Contexto } \\
\text { fónico }\end{array}$} & \multirow{2}{*}{ Interior } & Recuento & 1 & 119 & 0 & 120 \\
\hline & & & & Residuos corregidos & -1.0 & 3.8 & -3.7 & \\
\hline & & & \multirow{2}{*}{ Final } & Recuento & 3 & 104 & 13 & 120 \\
\hline & & & & Residuos corregidos & 1.0 & -3.8 & 3.7 & \\
\hline & & \multicolumn{2}{|l|}{ Total } & Recuento & 4 & 223 & 13 & 240 \\
\hline & \multirow{5}{*}{ Lectura } & \multirow{4}{*}{$\begin{array}{l}\text { Contexto } \\
\text { fónico }\end{array}$} & \multirow{2}{*}{ Interior } & Recuento & 0 & 56 & 0 & 56 \\
\hline & & & & Residuos corregidos & -6.1 & 6.4 & -1.2 & \\
\hline & & & \multirow{2}{*}{ Final } & Recuento & 52 & 57 & 3 & 112 \\
\hline & & & & Residuos corregidos & 6.1 & -6.4 & 1.2 & \\
\hline & & \multicolumn{2}{|l|}{ Total } & Recuento & 52 & 113 & 3 & 168 \\
\hline & \multirow{5}{*}{ Total } & \multirow{4}{*}{$\begin{array}{l}\text { Contexto } \\
\text { fónico }\end{array}$} & \multirow{2}{*}{ Interior } & Recuento & 1 & 175 & 0 & 176 \\
\hline & & & & Residuos corregidos & -6.7 & 7.9 & -3.6 & \\
\hline & & & \multirow{2}{*}{ Final } & Recuento & 55 & 161 & 16 & 232 \\
\hline & & & & Residuos corregidos & 6.7 & -7.9 & 3.6 & \\
\hline & & \multicolumn{2}{|l|}{ Total } & Recuento & 56 & 336 & 16 & 408 \\
\hline \multirow{15}{*}{ 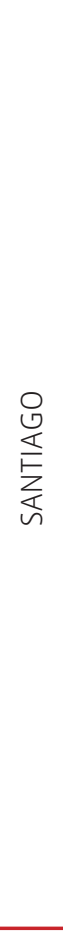 } & \multirow{5}{*}{ Entrevista } & \multirow{4}{*}{$\begin{array}{l}\text { Contexto } \\
\text { fónico }\end{array}$} & \multirow{2}{*}{ Interior } & Recuento & 0 & 120 & 0 & 120 \\
\hline & & & & Residuos corregidos & -3.1 & 6.2 & -5.2 & \\
\hline & & & \multirow{2}{*}{ Final } & Recuento & 9 & 87 & 24 & 120 \\
\hline & & & & Residuos corregidos & 3.1 & -6.2 & 5.2 & \\
\hline & & \multicolumn{2}{|l|}{ Total } & Recuento & 9 & 207 & 24 & 240 \\
\hline & \multirow{5}{*}{ Lectura } & \multirow{4}{*}{$\begin{array}{l}\text { Contexto } \\
\text { fónico }\end{array}$} & \multirow{2}{*}{ Interior } & Recuento & 4 & 52 & 0 & 56 \\
\hline & & & & Residuos corregidos & -4.6 & 5.7 & -2.4 & \\
\hline & & & \multirow{2}{*}{ Final } & Recuento & 47 & 54 & 11 & 112 \\
\hline & & & & Residuos corregidos & 4.6 & -5.7 & 2.4 & \\
\hline & & \multicolumn{2}{|l|}{ Total } & Recuento & 51 & 106 & 11 & 168 \\
\hline & & & Into & Recuento & 4 & 172 & 0 & 176 \\
\hline & & Contexto & 1110 & Residuos corregidos & -6.2 & 8.7 & -5.4 & \\
\hline & Total & fónico & IFin & Recuento & 56 & 141 & 35 & 232 \\
\hline & & & 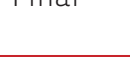 & Residuos corregidos & 6.2 & -8.7 & 5.4 & \\
\hline & & Total & & Recuento & 60 & 313 & 35 & 408 \\
\hline & & & Intorior & Recuento & 0 & 120 & 0 & 120 \\
\hline$\underline{z}$ & & Contexto & milemor & Residuos corregidos & -3.7 & 6.8 & -5.4 & \\
\hline 岂 & Entrevista & fónico & Find & Recuento & 13 & 81 & 26 & 120 \\
\hline ¿ & & & rillal & Residuos corregidos & 3.7 & -6.8 & 5.4 & \\
\hline & & Total & & Recuento & 13 & 201 & 26 & 240 \\
\hline
\end{tabular}




\begin{tabular}{|c|c|c|c|c|c|c|c|c|}
\hline \multirow{10}{*}{ 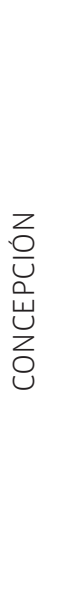 } & \multirow{5}{*}{ Lectura } & \multirow{4}{*}{$\begin{array}{l}\text { Contexto } \\
\text { fónico }\end{array}$} & \multirow{2}{*}{ Interior } & Recuento & 13 & 43 & 0 & 56 \\
\hline & & & & Residuos corregidos & -4.9 & 5.2 & -1.2 & \\
\hline & & & \multirow{2}{*}{ Final } & Recuento & 71 & 38 & 3 & 112 \\
\hline & & & & Residuos corregidos & 4.9 & -5.2 & 1.2 & \\
\hline & & \multicolumn{2}{|l|}{ Total } & Recuento & 84 & 81 & 3 & 168 \\
\hline & \multirow{5}{*}{ Total } & \multirow{4}{*}{$\begin{array}{l}\text { Contexto } \\
\text { fónico }\end{array}$} & \multirow{2}{*}{ Interior } & Recuento & 13 & 163 & 0 & 176 \\
\hline & & & & Residuos corregidos & -6.8 & 8.9 & -4.9 & \\
\hline & & & \multirow{2}{*}{ Final } & Recuento & 84 & 119 & 29 & 232 \\
\hline & & & & Residuos corregidos & 6.8 & -8.9 & 4.9 & \\
\hline & & \multicolumn{2}{|l|}{ Total } & Recuento & 97 & 282 & 29 & 408 \\
\hline \multirow{15}{*}{ 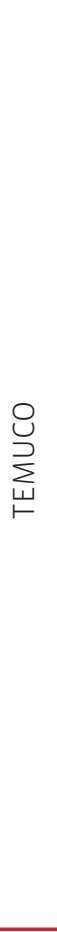 } & \multirow{5}{*}{ Entrevista } & \multirow{4}{*}{$\begin{array}{l}\text { Contexto } \\
\text { fónico }\end{array}$} & \multirow{2}{*}{ Interior } & Recuento & 1 & 119 & 0 & 120 \\
\hline & & & & Residuos corregidos & -3.3 & 5.5 & -4.1 & \\
\hline & & & \multirow{2}{*}{ Final } & Recuento & 13 & 91 & 16 & 120 \\
\hline & & & & Residuos corregidos & 3.3 & -5.5 & 4.1 & \\
\hline & & \multicolumn{2}{|l|}{ Total } & Recuento & 14 & 210 & 16 & 240 \\
\hline & \multirow{5}{*}{ Lectura } & \multirow{4}{*}{$\begin{array}{l}\text { Contexto } \\
\text { fónico }\end{array}$} & \multirow{2}{*}{ Interior } & Recuento & 15 & 41 & 0 & 56 \\
\hline & & & & Residuos corregidos & -5.6 & 6.0 & -1.2 & \\
\hline & & & \multirow{2}{*}{ Final } & Recuento & 81 & 28 & 3 & 112 \\
\hline & & & & Residuos corregidos & 5.6 & -6.0 & 1.2 & \\
\hline & & \multicolumn{2}{|l|}{ Total } & Recuento & 96 & 69 & 3 & 168 \\
\hline & \multirow{5}{*}{ Total } & \multirow{4}{*}{$\begin{array}{l}\text { Contexto } \\
\text { fónico }\end{array}$} & \multirow{2}{*}{ Interior } & Recuento & 16 & 160 & 0 & 176 \\
\hline & & & & Residuos corregidos & -7.1 & 8.5 & -3.9 & \\
\hline & & & \multirow{2}{*}{ Final } & Recuento & 94 & 119 & 19 & 232 \\
\hline & & & & Residuos corregidos & 7.1 & -8.5 & 3.9 & \\
\hline & & \multicolumn{2}{|l|}{ Total } & Recuento & 110 & 279 & 19 & 408 \\
\hline & & & int & Recuento & 0 & 120 & 0 & 120 \\
\hline & & Contexto & 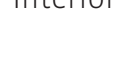 & Residuos corregidos & -2.0 & 3.1 & -2.3 & \\
\hline & Entrevista & fónico & Fin & Recuento & 4 & 111 & 5 & 120 \\
\hline & & & rillal & Residuos corregidos & 2.0 & -3.1 & 2.3 & \\
\hline$\frac{\vec{\sigma}}{4}$ & & Total & & Recuento & 4 & 231 & 5 & 240 \\
\hline$\stackrel{\frac{T}{\partial}}{\partial}$ & & & Into & Recuento & 3 & 53 & 0 & 56 \\
\hline & & Contexto & भIIU⿴囗十丁 & Residuos corregidos & -4.8 & 5.2 & -1.4 & \\
\hline & Lectura & fónico & & Recuento & 46 & 62 & 4 & 112 \\
\hline & & & rillal & Residuos corregidos & 4.8 & -5.2 & 1.4 & \\
\hline & & Total & & Recuento & 49 & 115 & 4 & 168 \\
\hline
\end{tabular}




\begin{tabular}{|c|c|c|c|c|c|c|c|c|}
\hline \multirow{5}{*}{ 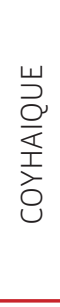 } & \multirow{5}{*}{ Total } & \multirow{4}{*}{$\begin{array}{l}\text { Contexto } \\
\text { fónico }\end{array}$} & \multirow{2}{*}{ Interior } & Recuento & 3 & 173 & 0 & 176 \\
\hline & & & & Residuos corregidos & -5.9 & 6.6 & -2.6 & \\
\hline & & & \multirow{2}{*}{ Final } & Recuento & 50 & 173 & 9 & 232 \\
\hline & & & & Residuos corregidos & 5.9 & -6.6 & 2.6 & \\
\hline & & \multicolumn{2}{|l|}{ Total } & Recuento & 53 & 346 & 9 & 408 \\
\hline \multirow{15}{*}{ 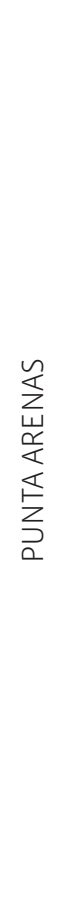 } & \multirow{5}{*}{ Entrevista } & \multirow{4}{*}{$\begin{array}{l}\text { Contexto } \\
\text { fónico }\end{array}$} & \multirow{2}{*}{ Interior } & Recuento & 3 & 117 & 0 & 120 \\
\hline & & & & Residuos corregidos & -2.6 & 4.3 & -3.4 & \\
\hline & & & \multirow{2}{*}{ Final } & Recuento & 13 & 96 & 11 & 120 \\
\hline & & & & Residuos corregidos & 2.6 & -4.3 & 3.4 & \\
\hline & & \multicolumn{2}{|l|}{ Total } & Recuento & 16 & 213 & 11 & 240 \\
\hline & \multirow{5}{*}{ Lectura } & \multirow{4}{*}{$\begin{array}{l}\text { Contexto } \\
\text { fónico }\end{array}$} & \multirow{2}{*}{ Interior } & Recuento & 9 & 47 & 0 & 56 \\
\hline & & & & Residuos corregidos & -4.2 & 4.8 & -1.8 & \\
\hline & & & \multirow{2}{*}{ Final } & Recuento & 55 & 51 & 6 & 112 \\
\hline & & & & Residuos corregidos & 4.2 & -4.8 & 1.8 & \\
\hline & & \multicolumn{2}{|l|}{ Total } & Recuento & 64 & 98 & 6 & 168 \\
\hline & \multirow{5}{*}{ Total } & \multirow{4}{*}{$\begin{array}{l}\text { Contexto } \\
\text { fónico }\end{array}$} & \multirow{2}{*}{ Interior } & Recuento & 12 & 164 & 0 & 176 \\
\hline & & & & Residuos corregidos & -5.7 & 7.0 & -3.7 & \\
\hline & & & \multirow{2}{*}{ Final } & Recuento & 68 & 147 & 17 & 232 \\
\hline & & & & Residuos corregidos & 5.7 & -7.0 & 3.7 & \\
\hline & & \multicolumn{2}{|l|}{ Total } & Recuento & 80 & 311 & 17 & 408 \\
\hline
\end{tabular}

